\title{
The Rate of Dissolution of Pre-reduced Iron in Molten Steel*
}

\author{
By Carlos E. SEATON,** Antonio A. RODRÍGUEZ,*** Manuel GONZÁLEZ*** \\ and Milton MANRIQUE ${ }^{* * *}$
}

\begin{abstract}
Synopsis
The rate of dissolution of sponge iron into molten steel has been studied. Reduced pellets from Midrex and $\mathrm{HyL}$ processes and pellets containing coal char were used. The dissolution of the pellets is accompanied by continuous gas evolution which is due mainly to the reduction of iron oxides remaining in the pellets by the carbon within the system. It was found that HyL pellets dissolved faster than Midrex and Midrex pellets dissolved faster than Sartenejas. The rate of heat transfer from the bath to the pellet was found to increase with increasing gas evolution. The melting process was simulated by a mathematical model by assuming heat transfer control. This model allowed the calculation of the heat transfer coefficient as a function of the instantaneous radius of the pellet.
\end{abstract}

\section{Introduction}

The technology of electric furnace steelmaking has undergone significant development over the last twenty years. Contributing factors to that growth are the advances in the furnace design and the development of the direct reduction processes which place the sponge iron in a competitive situation with scrap. This also contributed to establish the technology Direct-Reduction-Electric Furnace as an alternative to the Blast-furnace-B.O.F.

Directly reduced iron constitutes a relatively new charging material to the steelmaking process. Unlike scrap and pig iron, the DRI is characterized by a high porosity, low density, low thermal conductivity, high surface area, a relatively high oxygen content and intermediate carbon percentages. Obviously, these differences should introduce changes in the steelmaking practice. Pilot plant and mill trials have demonstrated that the use of DRI leads to improved yield and productivity and decrease electrode and lime consumption. This advantages are due first, to the better knowledge of charge composition which allows more accurate predictions of final analysis and closer calculation of lime addition; and second, to a decrease in the tap to tap time because of the pre-refining achieved during continuous feeding. ${ }^{1-5)}$

Because of its importance to the understanding of DRI-Electric Furnace steelmaking, the behavior of DRI pellets in both, slag and molten steel have been recently investigated. Elliott et al. ${ }^{6)}$ studied the heating and melting of DRI pellets in hot slag of composition similar to that of electric furnace operation. Their work showed that the heating of the pellet is accompanied by continuous evolution of carbon monoxide $(94 \%)$ and dioxide $(6 \%)$. Gas evolution was found to influence the rate of heat transfer from the molten slag to the pellet. Indeed, the larger the gas evolution, the greater the heat transfer coefficient, and therefore, the rate of heat transfer to the pellet. Elliott and coworkers calculated, based on a theoretical model, the melting time of the pellets. The calculations indicated that the melting rate of the pellets in the metallization range between $80 \%$ and $90 \%$ increased with decreasing percentage of metallization and by decreasing the size of the pellet. Sato et al. ${ }^{7)}$ investigated the rate of melting of cylindrical pellets in a carbon saturated melt. According to their work, the melting rate of the pellets was enhanced by increasing the carbon content of the bath, carbon content of the pellet and residual oxygen content of the pellet. In later work, Sato et al.$^{8)}$ measured the melting rate as a function of gas evolution from the pellet. They demonstrated that the melting rate increases with decreasing gangue content and decreasing melting point of the slag. As in their previous work, an increase on the residual oxygen content of the pellet and carbon content of the bath increased the melting rate. The apparent activation energy for melting was $33 \mathrm{kcal} / \mathrm{mol}$; value from which they concluded that the process was controlled by the rate of heat transfer and the reduction of pellets charged with and without $\mathrm{Fe}_{2} \mathrm{O}_{3}$.

The melting of the pellets in a carbon saturated melt, as properly stated by Sato et al. ${ }^{7)}$ is heavily influenced by the reduction of iron oxides in the pellet by carbon in the melt. However, as demonstrated by Yeong Ukim and Pehlke, ${ }^{9)}$ Olsson et al., ${ }^{10)}$ and Szekely et al. ${ }^{11)}$; the melting rate of a low-carbon steel in a carbon saturated melt is controlled by the diffusion of carbon from the melt to the solid-liquid interface. This could be the case for pellets with low carbon percent and high metallization, and under these conditions, diffusion of carbon can not be neglected. Therefore, the determination of the rate controlling step based on the value of the apparent activation energy should be taken cautiously. The system is too complicated, and therefore a more careful approach is required. For instance, the work should be carried under conditions where one of the steps already mentioned is more likely to be the rate controlling one. Such approach is taken here where the bath is low in carbon and the estimated melting temperature of the pellet is close to that of the bath.

* Presented to the 1st Venezuela-Japan Symposium on Iron and Steelmaking, May 1980, in Caracas. Manuscript received August 24, 1981. (C) 1983 ISIJ

** Dept. of Metallurgy, Michigan Technological University, Houghton, Michigan 49931, U.S.A.

On leave from Dept. de Ciencias de los Materiales, Universidad Simón Bolívar, Apartado, Caracas 1080, Venezuela.

*** Dept. de Ciencias de los Materiales, Universidad Simón Bolívar, Apartado, Caracas 1080, Venezuela. 
Thus, the purpose of the present work is to estimate qualitatively the effect of the main parameters of the process on the rate of dissolution of pre-reduced pellets in molten steel. The experimental tests were performed with pellets from Midrex, HyL processes, and also with a third type of pellets containing coal char. The overall process has been simulated in the computer by using a mathematical model where the heat transfer rate from the bulk of the molten bath to the melting interface is the rate controlling step.

The mathematical approach was similar to that followed by previous investigators. ${ }^{12-14}$ )

\section{Mathematical Formulation}

The system considered in the present work consists of a spherical pellet of radius $R_{0}$ and initial temperature $T_{0}$. The pellet is brought into contact with a low-carbon steel melt which is at temperature $T_{B}$, greater than the melting temperature of the pellet, $T_{m}$. Under these conditions, the system is assumed to be controlled by the rate of heat transfer from the bulk of the molten bath to the melting interface. In order to be able to formulate mathematical expressions describing the behavior of the process, the following tenable assumptions are made:

(1) The physical properties of the system remain constant during the process.

(2) The temperature profile within the pellet is symmetrical with respect to the radial coordinate.

(3) The melting temperature of the pellet as well as the temperature of the molten bath remain constant during the process.

(4) The heat transfer from the bulk of the molten bath to the solid-liquid interface is due to convective mechanism.

A heat balance made on the system is expressed by the well-known partial differential equation:

$$
\alpha\left[\frac{\partial^{2} \mathcal{T}}{\partial r^{2}}+\frac{2}{r} \frac{\partial \mathcal{T}}{\partial r}\right]=\frac{\partial \mathcal{T}}{\partial t} 0 \leq r \leq r(t)
$$

The initial and boundary conditions associated with Eq. (1) are:

$$
\begin{aligned}
& T(r, t \leq 0)=T_{0} \ldots \ldots \ldots \ldots \\
& \left.\frac{\partial T}{\partial r}\right|_{r=0, t>0}=0 \ldots \ldots \ldots \ldots \\
& T(r=r(t), t>0)=T_{m}
\end{aligned}
$$

The rate of advance of the melting interface is given by the equation:

$$
\left.k \frac{\partial T}{\partial r}\right|_{r=r(t), t>0}-h\left(T_{B}-T_{m}\right)=\rho \Delta H \frac{d r(t)}{d t}
$$

Equations (1) to (5) expressed in dimensionless form are respectively as follows:

$$
\begin{aligned}
& \frac{\partial^{2} \theta}{\partial \eta^{2}}+\frac{2}{\eta} \frac{\partial \theta}{\partial \eta}=\frac{\partial \theta}{\partial \tau^{\prime}} \quad 0 \leq \eta \leq \psi\left(\tau^{\prime}\right) \ldots \ldots \ldots \ldots \ldots \ldots \ldots \ldots \ldots \ldots \ldots \ldots \\
& \theta\left(\eta, \tau^{\prime} \leq 0\right)=-1
\end{aligned}
$$

$$
\begin{aligned}
& \left.\frac{\partial \theta}{\partial \eta}\right|_{\eta=0, \tau^{\prime}>0}=0 \ldots \ldots \ldots \ldots \ldots \ldots \ldots \ldots \ldots \ldots \\
& \left.\frac{\partial \theta}{\partial \eta}\right|_{\eta=\psi\left(\tau^{\prime}\right), \tau^{\prime}>0}-B_{i} \theta^{*}=\Omega \frac{\mathrm{d} \psi}{\mathrm{d} \tau^{\prime}}
\end{aligned}
$$

where,

$$
\begin{aligned}
& \theta=\frac{T-T_{m}}{T_{m}-T_{0}} ; \quad \tau^{\prime}=\frac{\alpha t}{R_{0}^{2}} ; \quad \eta=\frac{r}{R_{0}} \\
& \phi\left(\tau^{\prime}\right)=\frac{r(t)}{R_{0}} ; \quad \Omega=\frac{\Delta H}{C_{p}\left(T_{m}-T_{0}\right)} . \\
& B_{i}=\frac{h R_{0}}{k} ; \quad \theta^{*}=\frac{T_{B}-T_{m}}{T_{m}-T_{0}} \ldots \ldots . .
\end{aligned}
$$

The system is described by Eqs. (6) to (9). No analytical solution exists for this set of dimensionless equations. Chuang and Szekely ${ }^{12)}$ and Ehrich et al. ${ }^{13}$ ) have used successfully the Green's function method to transform the partial differential equations describing melting and solidification problems into the integral form, in terms of the initial and boundary conditions.

By using the Green's function method and after some mathematical manipulation, the general solution of Eqs. (6) to (9) can be written as follows:

$$
\begin{aligned}
\theta\left(\eta, \tau^{\prime}\right)= & \left.\int_{0}^{1} 4 \pi \xi^{2}\left(\Omega \frac{d \psi}{d \tau^{\prime}}+B_{i} \theta^{*}\right) \cdot G\right|_{\xi=\psi} d \tau \\
& -\left.\int_{0}^{1} \pi \xi^{2} \cdot G\right|_{\tau=0} d \xi \ldots \ldots \ldots \ldots \ldots \ldots \ldots \ldots \ldots \ldots
\end{aligned}
$$

Where $G$ is the Green's function expressed in spherical coordinates as follows:

$$
\begin{aligned}
G\left(\eta, \tau^{\prime} \mid \xi, \tau\right)= & \frac{1}{8 \pi \eta \xi \sqrt{\pi\left(\tau-\tau^{\prime}\right)}} \\
& \times\left\{\exp \left(-(\eta-\xi)^{2} / 4 \pi\left(\tau-\tau^{\prime}\right)\right)\right. \\
& \left.-\exp \left(-(\eta+\xi)^{2} / 4 \pi\left(\tau-\tau^{\prime}\right)\right)\right\}
\end{aligned}
$$

Equation (13) describes the temperature distribution within the pellet, as a function of $\eta$ and $\tau^{\prime}$, in terms of the initial and boundary conditions. This equation contains two unknowns, $\phi\left(\tau^{\prime}\right)$ the instantaneous position of the melting interface, and $\theta\left(\eta, \tau^{\prime}\right)$ the dimensionless temperature. Equation (13) could be integrated numerically but it has some difficulties such as the singularity of $G$ as $\eta \rightarrow 0, \xi \rightarrow 0$ and $\tau^{\prime} \rightarrow \tau$. The general technique used to overcome these difficulties is described by Chuang and Szekely. ${ }^{12)}$. Using this technique Eq. (13) is expressed as follows:

$$
\begin{aligned}
& \theta\left(\eta, \tau^{\prime}\right)=\left.\sum_{1}^{\mathrm{N}}\left(\Omega \frac{d \phi}{d \tau^{\prime}}+B_{i} \theta^{*}\right) \int_{\tau_{n-1}^{\prime}}^{\tau_{n}^{\prime}} 4 \pi \xi^{2} \cdot G\right|_{\xi=\psi} d \tau \\
& -\left.\sum_{1}^{\mathrm{M}} \int_{\eta_{m-1}}^{\eta_{m}} 4 \pi \xi^{2} \cdot G\right|_{\tau=0} d \xi
\end{aligned}
$$

Equation (15) can be applied at a particular position within the domain, where the temperature is known; for example at the melting interface, to determine the other unknown which is the melting rate. By knowing the melting rate, the temperature at any point of the domain can be obtained by using again Eq. (15). A computer program was used to evaluate Eq. (15) and compare theoretical predictions with the 
experimental results.

\section{Experimental Procedure}

The melting tests were performed in an inductiontype furnace using a $6 \mathrm{~kg}$ capacity magnesia crucible. Midrex and HyL reduced pellets provided by SIDOR were dissolved in the molten bath. A third type of pellets produced in the laboratory using coal char (81.6\% C, $14 \%$ v.m., $4.2 \%$ ash) as a solid reductant were also used. These pellets were reduced prior to the dissolution experiments. Table 1 shows the composition of these three types of pellets.

The molten bath was decarburized previously by adding iron ore to reduce the carbon content between $0.10 \%$ and $0.15 \%$. The bath was slagged prior to the test. A Pt-Rh immersion thermocouple was used to measure the bath temperature. Two different techniques were used in these experiments. One consisted of dropping the pellet on the bath, allowing it to move freely on the surface of the liquid metal observing its behavior and recording the time it takes to dissolve completely. The other technique consisted of dipping the pellet into the bath while it is being held by a ceramic tube attached to it with high temperature refractory cement. In some of these experiments, a 0.003 in-diameter Chromel-Allumel insulated thermocouple was attached to the center of the pellet to measure the temperature change at this point throughout the dissolution process. Partially dissolved pellets were selected to be analyzed by scanning electron microscopy and determine structural changes occurring during the melting test.

\section{Experimental Results}

The three types of pellets used in the experiments: Midrex, HyL and Sartenejas have shown a similar behavior during the dissolution process. Due to its low density, these pellets float on the surface of the melt and tend to move towards the wall of the crucible. The slag which is being produced during the process accumulates continuously on the surface of the melt reducing the rate of dissolution of the floating pellets. Thus, it was necessary to remove the slag prior to each test to assure a good dissolution process. The experimental results have indicated that Midrexand HyL-type pellets took between $15 \mathrm{sec}$ and $25 \mathrm{sec}$ to dissolve, meanwhile Sartenejas-type pellets took from 25 to $70 \mathrm{sec}$.

The interaction of the pellet with the bath generates a strong agitation. This is due to the evolution of the gases trapped in the pores of the pellet and those being produced during the process by chemical reactions. That is, carbon monoxide and carbon dioxide formed

Table 1. Chemical composition of reduced pellets.

\begin{tabular}{l|ccccc}
\hline \multicolumn{1}{c|}{ Type } & $\begin{array}{c}\% \mathrm{Fe} \\
\text { metallic }\end{array}$ & $\% \mathrm{FeO}$ & $\begin{array}{c}\% \mathrm{Fe} \\
\text { Total }\end{array}$ & \% $\mathrm{SiO}_{2}$ & $\% \mathrm{CaO}$ \\
\hline Sartenejas & 76.1 & 2.2 & 85 & 3.3 & 0.14 \\
Midrex & 82.9 & 0.7 & 88 & 3.7 & 0.16 \\
HyL & 69.7 & 7.7 & 81 & 2.9 & 0.21 \\
\hline
\end{tabular}

by reaction of the oxygen in the bath or in the unreduced iron oxide with the carbon in the pellet. The extent of agitation increased with decreasing pellet metallization. Sudden expulsion of the pellet out of the melt were observed for percentages of metallization below $60 \%$. Similar behavior was reported by Sato et al. ${ }^{8)}$ with pellets over $93 \%$ metallization.

The experiments performed using pellets that were completely dipped into the melt confirmed the strong agitation produced by gas evolution. These also allowed the evaluation of the difference between the rate of dissolution of the three types of pellets used in this work. It was observed that Midrex- and HyLtype pellets melt at a higher melting rate than the Sartenejas ones. This behavior is mainly related to the difference in composition and physical structure of three types of pellets.

Pellets dipped into the melt for a few second were analyzed by scanning electron microscopy. This technique allowed to determine the structural changes occurring during the melting process.

Photograph 1 shows the surface structure of a Midrex pellet immersed in the melt during $5 \mathrm{sec}$. This photograph shows that the pellet surface in contact with the bath is highly porous. Notice the tunnellike appearance which clearly indicates the continuous gas evolution that takes place during the dissolution process. Photograph 2 illustrates in more detail the characteristics of pore observed at the surface.

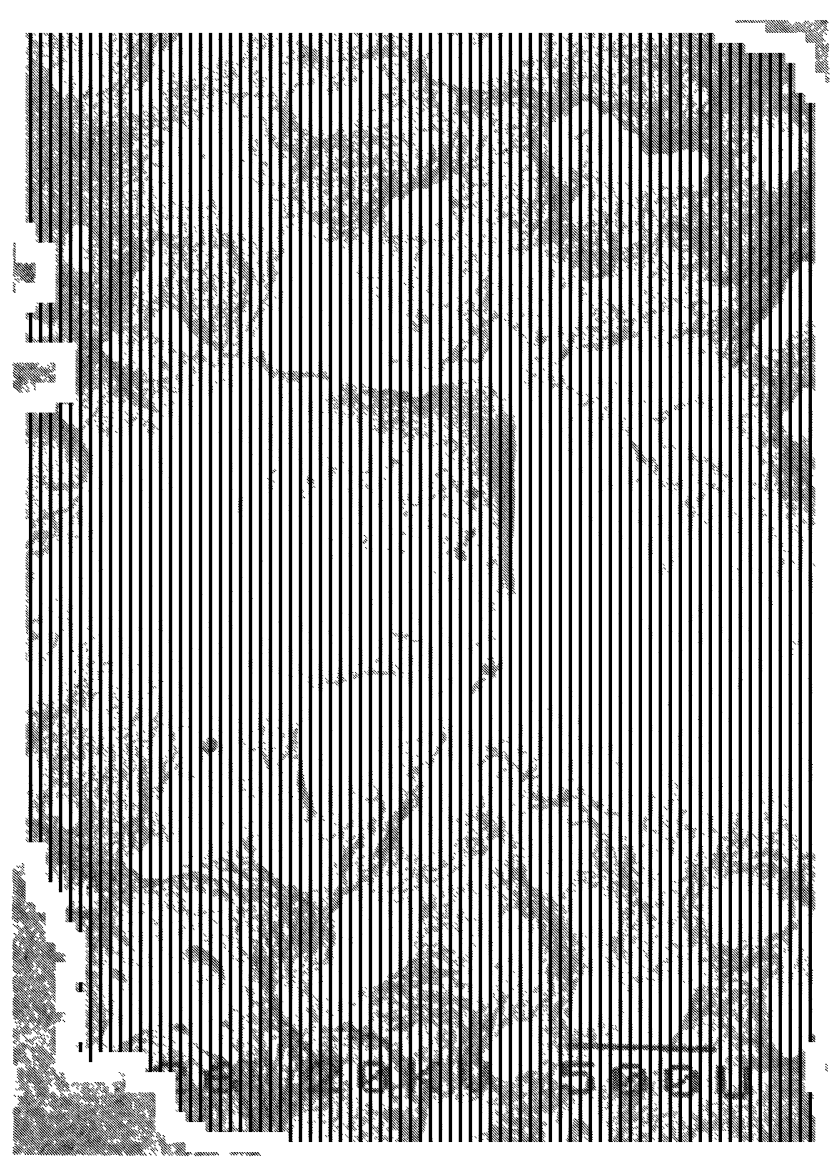

Photo. 1. Surface structure of a midrex pellet after immersion in molten steel for $5 \mathrm{sec}$ 


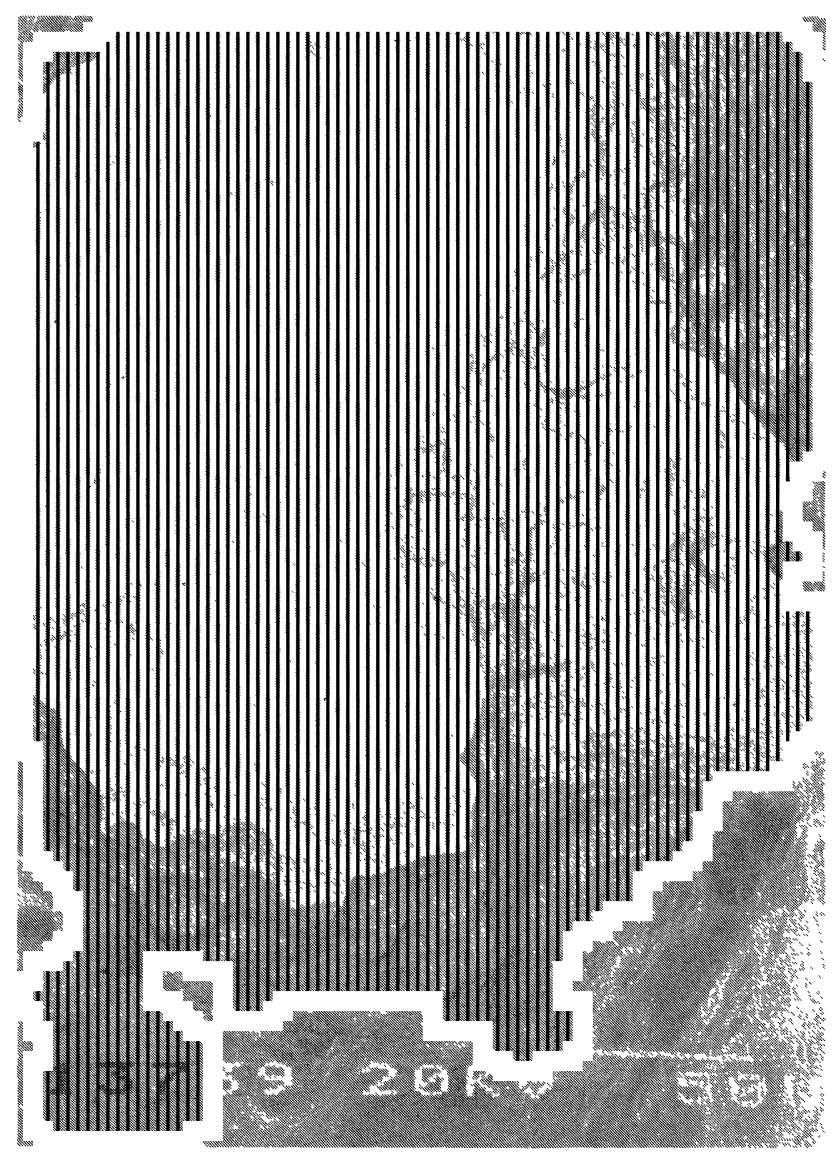

Photo. 2. Characteristics of the pores observed at the surface of a midrex pellet after immersion in molten steel for $5 \mathrm{sec}$.

Photograph 3 shows the internal structure of a partially dissolved Midrex pellet. The internal structure is equal to that observed in the reduced pellet prior to the dissolution test. This difference between the surface and the center of the pellet demonstrates that the resulting surface structure is only a localized effect produced by the pellet-bath interaction.

\section{Discussion}

The melting or dissolution of pellets in liquid steel is a complex process due to the simultaneous interplay of different physical and chemical phenomena. Sato et al. ${ }^{7-8)}$ have identified four main stages during the melting process. They are:

1) heat transfer from the melt to the pellet

2) carbon transfer from the iron melt to the melting interface

3) iron transfer from the pellet to the melt

4) reduction of iron oxides in the pellet by carbon in the melt.

Stages 1) and 3) apply also to this work; however, the pellet used here has a higher carbon content than the melt. Therefore, stage 2) should be reversed and the interaction between the ferrous oxide and the carbon of the pellet should be stronger than the interaction with the carbon of the melt.

Under the experimental conditions of this work, the most influential aspects of the melting process are

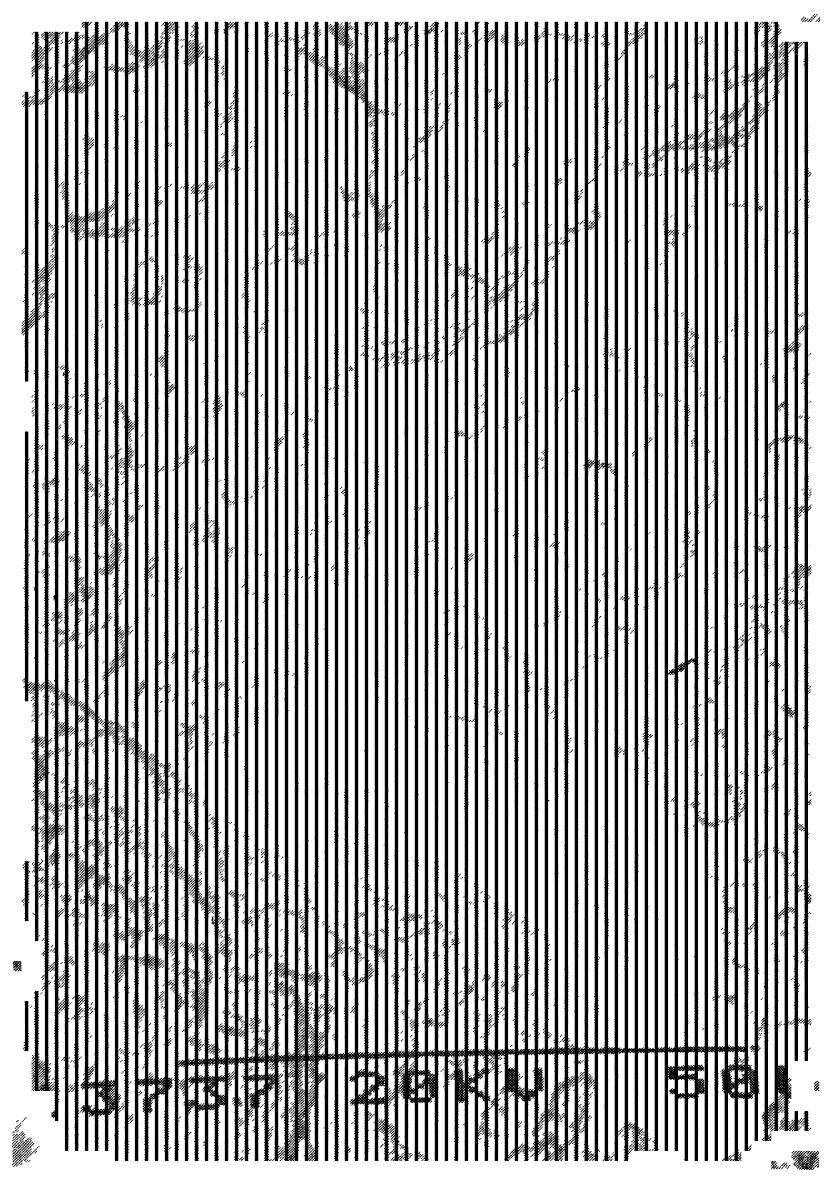

Photo. 3. Internal structure of a midrex pellet after immersion in molten steel for $5 \mathrm{sec}$.

the chemical interaction inside the pellet and at the pellet-melt interface, and the rate of heat transfer from melt to pellet. Elliott et al. ${ }^{6)}$ demonstrated that the dissolution of pellets into molten slag is depending upon the rate of heat transfer which is influenced by the gas evolving from the pellet produced by the reduction of the ferrous oxide by the carbon wthin the pellet. Thus, Elliott et al. ${ }^{6}$ ) proposed the following possible mechanism:

$$
\begin{aligned}
\mathrm{FeO}(\mathrm{s})+\mathrm{Fe}_{3} \mathrm{C}(\mathrm{s}) & =4 \mathrm{Fe}(\mathrm{s})+\mathrm{CO}(\mathrm{g}) \\
2 \mathrm{FeO}(\mathrm{s})+\mathrm{Fe}_{3} \mathrm{C}(\mathrm{s}) & =5 \mathrm{Fe}(\mathrm{s})+\mathrm{CO}_{2}(\mathrm{~g})
\end{aligned}
$$

Reactions (16) and (17) assume that the carbon is present in the form of cementite. Figure 1 shows the spectrum resulting from the analysis of fractured surfaces of the reduced Midrex and HyL pellets. This analysis was done by using Auger electron spectroscopy. The fact that the cementite peak was not present, and the decrease in the intensity of the graphite peak after argon bombardment, indicates that the carbon within both, the Midrex and HyL pellets is more likely to be in the form of graphite or carbon soot deposited internally within the pellet during the reduction process. Further examination by standard metallographic methods did not show even traces of cementite. The results have also shown that the melting process is accompanied by a continuous gas evolution. Theoretical calculations, based on the 

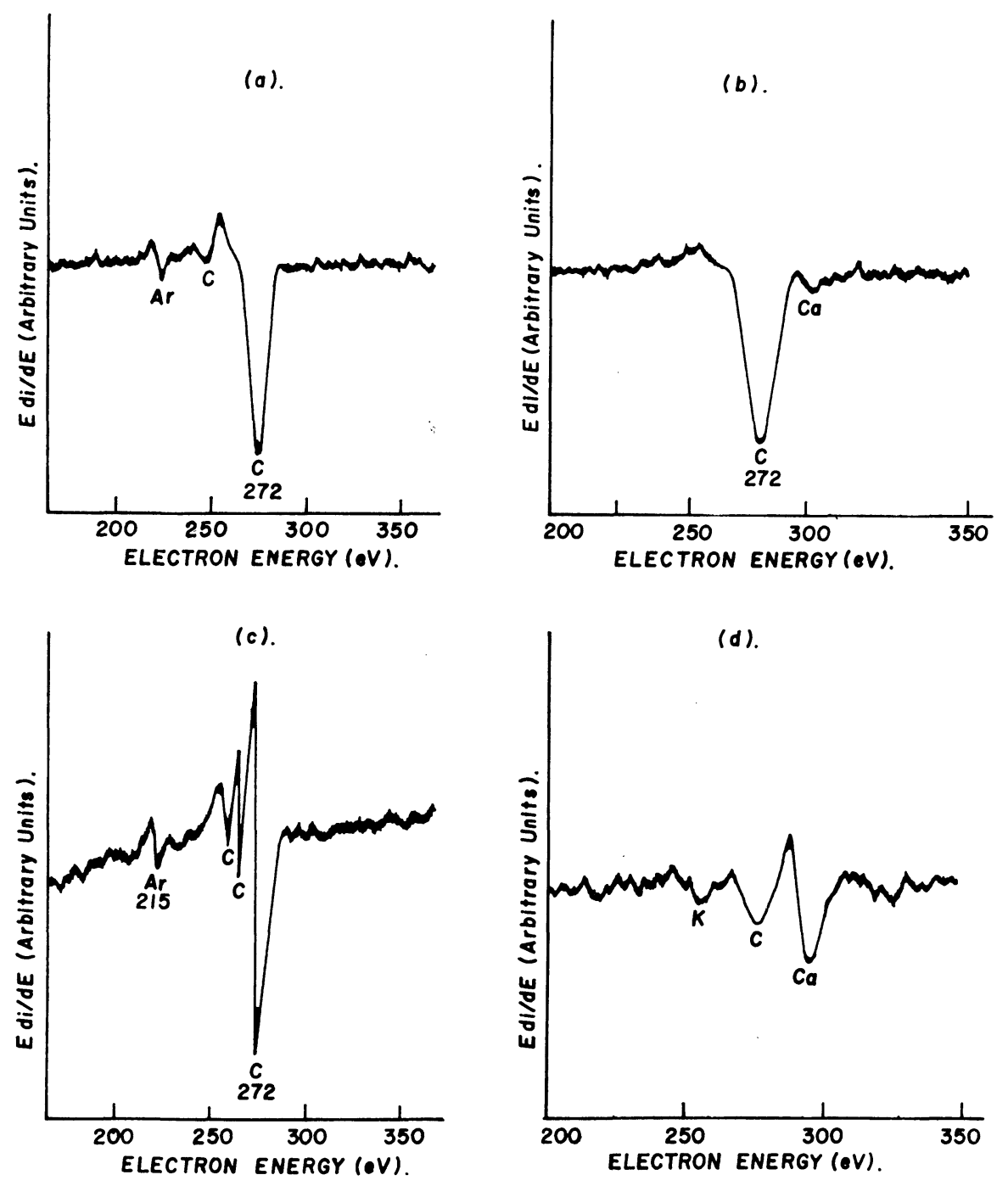
(a) Graphite
(b) Carbon inside a midrex type pellet
(c) Iron carbide
(d) Same as (b) after $40 \mathrm{~min}$ of argon bombardment

Fig. 1. AES spectra of carbon. carbon and oxygen content of the pellet have given volumes of 150 and $280 \mathrm{~cm}^{3}$ of gas evolved for the pellets Midrex and HyL, respectively. These values agree well with those of 280 and $1000 \mathrm{~cm}^{3}$ reported by previous investigators. ${ }^{5-8)}$ Based on these observations, it is possible to consider two mechanisms to account for the continuous gas evolution reported in this work, they are:

(1) Chemical reactions between the graphite or carbon deposited on the surface of the pellet grains with the oxygen entrapped within the pellets to produce mainly CO. This $\mathrm{CO}$ could react with the ferrous oxide reducing it and generating $\mathrm{CO}_{2}$. Therefore the following reactions are possible:

$$
\begin{aligned}
& \mathrm{G}(\text { pellet })+1 / 2 \mathrm{O}_{2}(\text { pellet })=\mathrm{CO}(\mathrm{g}) \\
& \mathrm{FeO}(\mathrm{s})+\mathrm{CO}(\mathrm{g})=\mathrm{CO}_{2}(\mathrm{~g})+\mathrm{Fe}(\mathrm{s}) \\
& \mathrm{CO}_{2}(\mathrm{~g})+\mathrm{G}(\mathrm{s})=2 \mathrm{CO}(\mathrm{g}) \ldots \ldots \ldots \ldots . .
\end{aligned}
$$

(2) Chemical reaction between the carbon of the pellet and the oxygen dissolved in the melt to produce CO. This reaction could occur at the pelletmelt interface and account for the observed tunnellike appearance of the pellet surface.

The experimental measurements of the pellets heating rate, and their comparison with the theoretical predictions are shown in Figs. 2 to 5 . Figures 2 and 3 correspond to Midrex pellets of different sizes tested under initial pellet and bath temperature. In both cases, the behavior is the same. That is, the heating rate is rather low during the early steps of the process, and increases quite rapidly toward the final dissolution stages. Comparing both figures, it can also be seen that increasing the pellet radius and decreasing its initial temperature decreases the dissolution time. Figures 4 and 5 represent the results for the HyL pellets. The behavior is similar. Notice, however, that the heating rate measured for the $\mathrm{HyL}$ pellet is greater than that reported for the Midrex ones. This is consistent with the higher value of the heat transfer coefficient required to fit the theoretical curve to the experimental one.

The values of the heat transfer coefficient from the melt to the pellet were determined by curve-fitting the calculated results with the experimental measurement of the temperature at the pellet center. Initially, constant values of $h$ between $0.20 \mathrm{cal} \cdot \mathrm{cm}^{-2} \cdot \mathrm{s}_{\mathrm{g}}^{-1}{ }^{\circ} \mathrm{k}^{-1}$ and $0.60 \mathrm{cal} \cdot \mathrm{cm}^{-2} \cdot \mathrm{s}_{\mathrm{g}}^{-1} \mathrm{k}^{-1}$ were tried. The fitting improves with increasing values of $h$, but there were still considerable discrepancies for $h=0.60$. These difficulties were associated with the changes on the radius and physical properties of the pellets during 


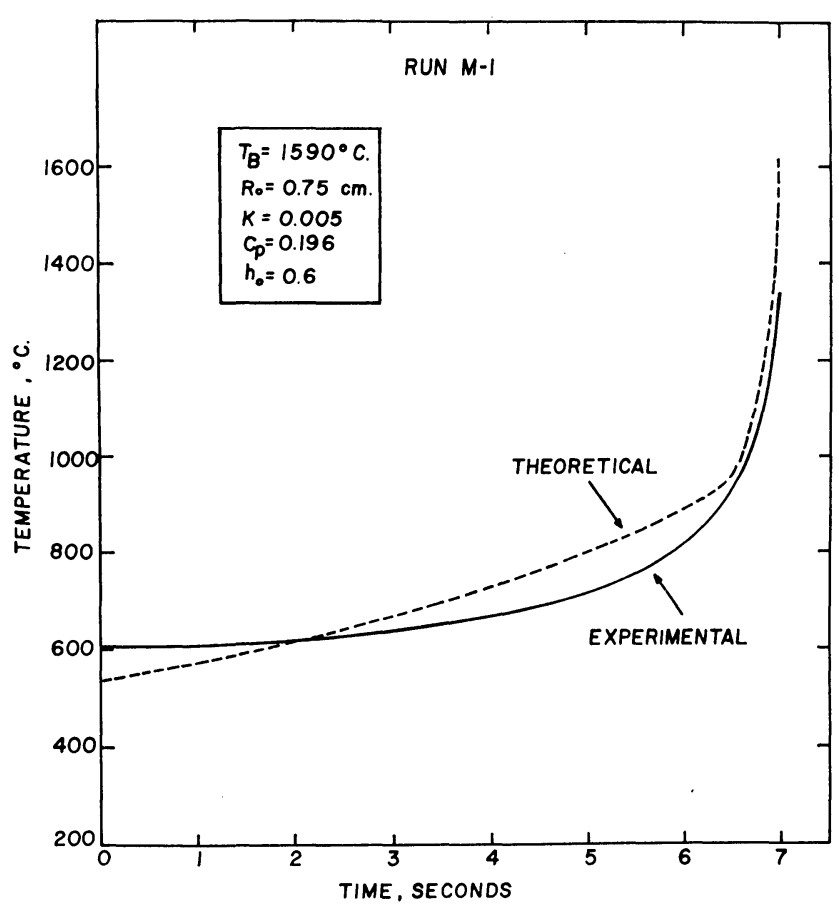

Fig. 2. Temperature $v s$. time at the center of a midrex pellet immersed in liquid steel at $1590^{\circ} \mathrm{C}$.

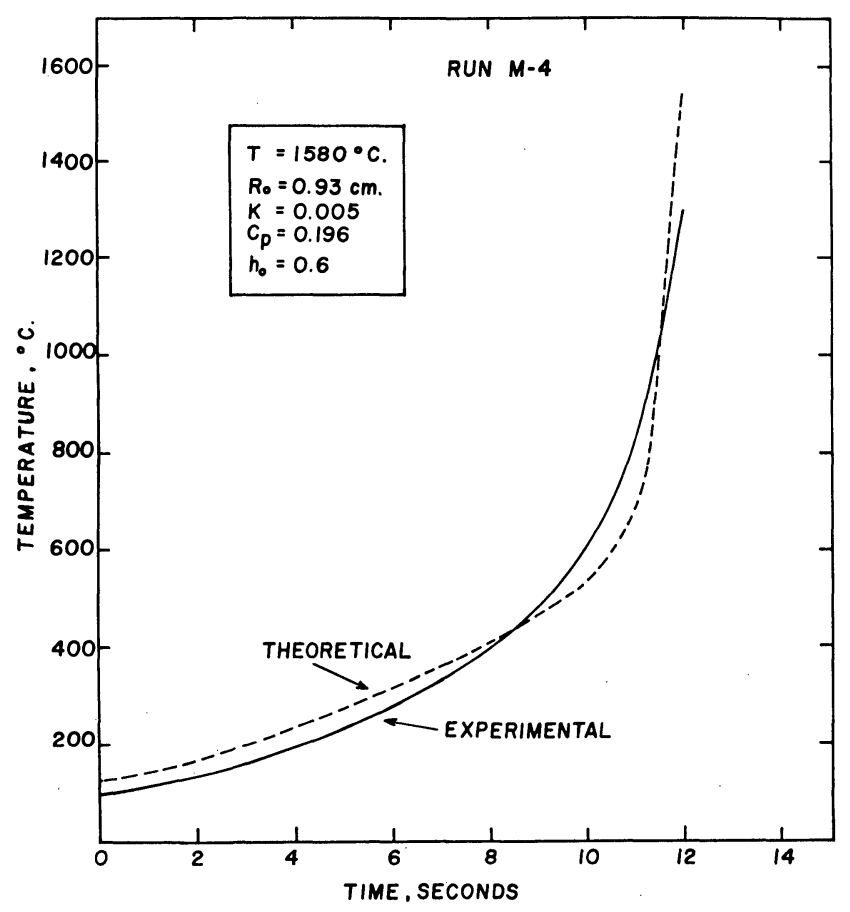

Fig. 3. Temperature $v s$. time at the center of a midrex pellet immersed in liquid steel at $1580^{\circ} \mathrm{C}$.

the melting process. Better fittings were obtained, as it is indicated in Figs. 2 to 5, by using an expression $^{14)}$ for the variation of the heat transfer coefficient with the pellet radius.

$$
h=h_{o} / \sqrt{r}
$$

The best fitting was obtained with values of $h_{o}=$ $0.6 \mathrm{cal} \cdot \mathrm{cm}^{-2 / 3} \cdot \mathrm{sg}_{\mathrm{g}^{-1}} \mathrm{k}^{-1}$ and $h_{o}=0.7$ for the pellets Midrex and HyL respectively. These values agree well with those reported by previous investigators. ${ }^{14,15)}$

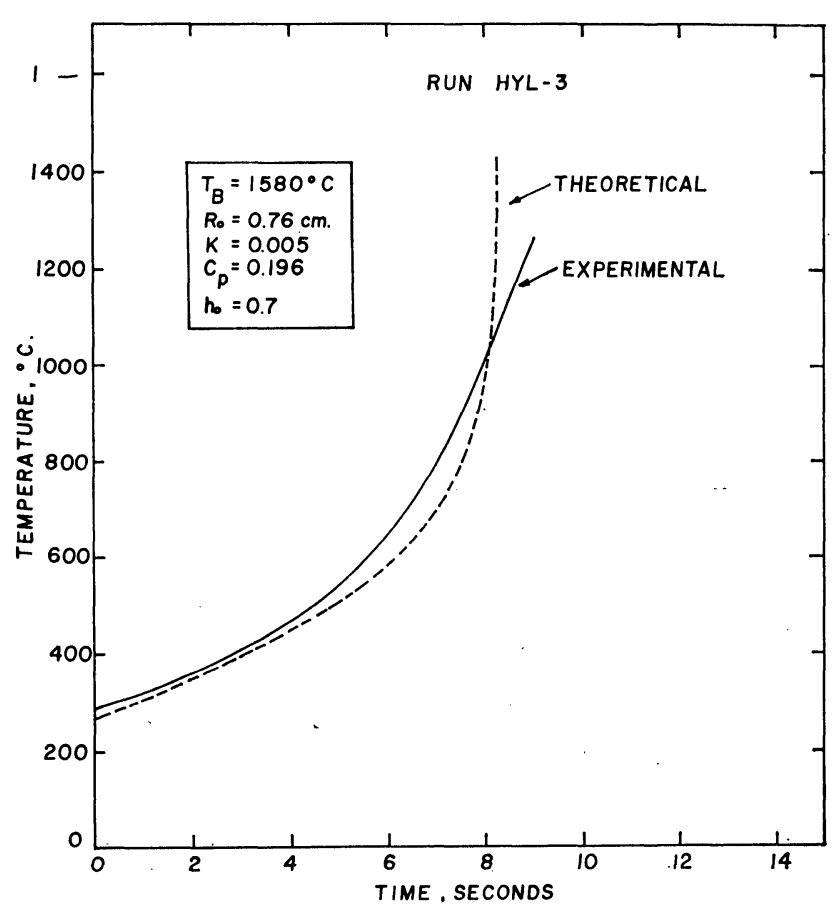

Fig. 4. Temperature $v s$. time at the center of an HyL pellet immersed in liquid steel at $1580^{\circ} \mathrm{C}$.

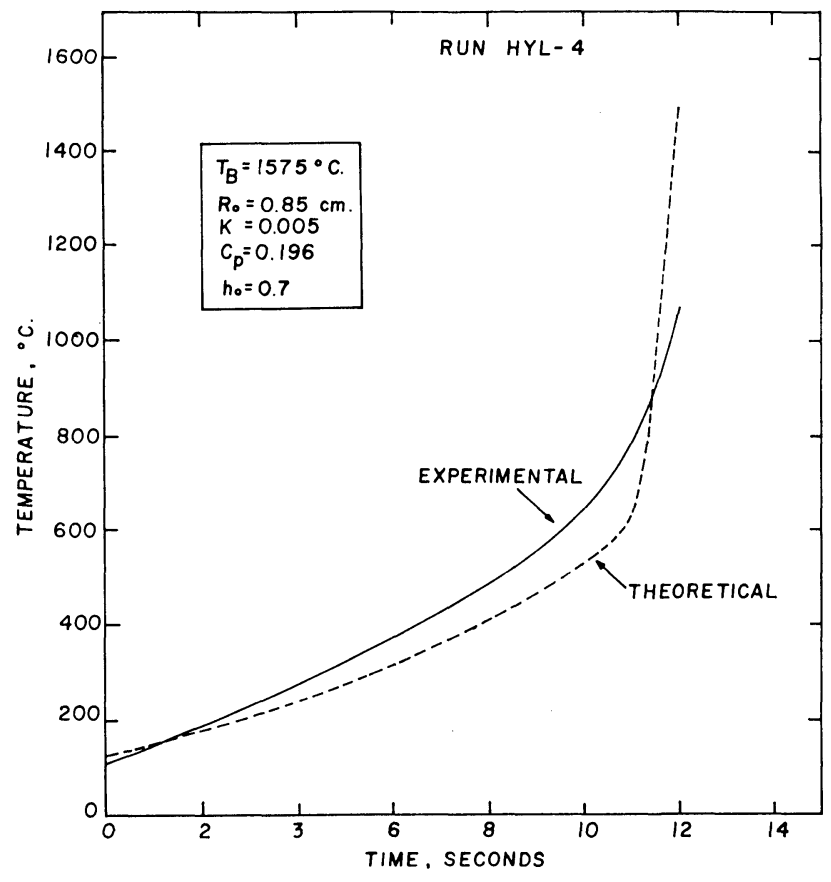

Fig. 5. Temperature vs. time at the center of an HyL pellet immersed in liquid steel at $1575^{\circ} \mathrm{C}$.

The higher value of the heat transfer coefficient from the melt to the HyL pellet is consistent with the larger melting rate obtained for those pellets.

The results have shown that there is a larger volume of gas generated, higher internal heating rate and larger rate of heat transfer from melt to pellets during the dissolution of the HyL pellets. In spite of the differences in thermal properties that may arise due to the reduction process and discrepancies in the percentage of metallization, it is believed that the key 
factor during the melting process is the gas evolution from the pellets and its influence in the heat transfer process through the solid liquid interface.

\section{Conclusions}

The melting of pre-reduced iron pellets in liquid steel is a complex phenomena because of the interplay of several variables that can not be accounted for in a mathematical simulations of the melting process. Nonetheless, the results of the theoretical model based on simplified assumptions and those of experimental observations allow the stating of the following conclusions:

(1) The rate of heat transfer from the melt to the pellet is strongly influenced by the continuous gas evolution occurring during the process. The higher the gas evolution the faster the melting rate.

(2) The gas evolved during the melting process is mainly carbon monoxide formed by chemical reactions between the carbon deposited within the pellet and oxygen from unreduced iron oxides or that dissolved in the liquid steel.

(3) The mathematical model based on heat transfer control describes the process with reasonable accuracy.

\section{Nomenclature}

$B_{i}$ : Biot number

$C_{p}:$ Specific heat capacity of molten bath $\left(\mathrm{QM}^{-1}\right.$ $\mathrm{T}^{-1}$ )

$G$ : Green's function

$h$ : heat transfer coefficient $\left(\mathrm{QL}^{-2} \mathrm{t}^{-1} \mathrm{~T}^{-1}\right)$

$h_{o}:$ coefficient $\left(\mathrm{QL}^{-3 / 2} \mathrm{t}^{-1} \mathrm{~T}^{-1}\right)$

$\Delta H:$ latent heat of phase change $\left(\mathrm{QM}^{-1}\right)$

$k$ : thermal conductivity of molten bath $\left(\mathrm{QL}^{-1}\right.$ $\left.\mathrm{t}^{-1} \mathrm{~T}^{-1}\right)$

$R_{0}$ : initial radius of the pellet $(\mathrm{L})$

$r$ : radial coordinate $(\mathrm{L})$

$r(t)$ : time-dependent position of the phase bound$\operatorname{ary}(\mathrm{L})$

$t:$ time $(\mathrm{t})$

T: Temperature $(\mathrm{T})$

$T_{0}:$ initial temperature of the pellet $(\mathrm{T})$

$\mathcal{T}_{B}:$ bulk temperature $(\mathrm{T})$

$T_{m}:$ melting point $(\mathrm{T})$

$\alpha$ : Thermal diffusivity, $k / p C p\left(\mathrm{~L}^{2} \mathrm{t}^{-1}\right)$

$\eta$ : dimensionless radial coordinate

$\xi$ : Green's parameter

$\theta:$ dimensionless temperature

$\theta^{*}:$ dimensionless bulk temperature

$\Omega$ : dimensionless parameter $\rho:$ density of molten bath $\left(\mathrm{ML}^{-3}\right)$

$\tau:$ Green's parameter

$\tau^{\prime}$ : dimensionless time

$\phi\left(\tau^{\prime}\right)$ : dimensionless time-dependent position of the phase boundary

\section{Acknowledgements}

The authors would like to express their gratitude to Dr. John Elliott for his valuable comments, and to Messrs. Mario Rodríguez and Victor Lamas for their assistance in the auger work.

This project has been partially financed by the Organization of the American States (O.E.A.) through the Program for the Scientific and Technological Development.

\section{REFERENGES}

1) R. M. Smailer, H. B. Jensen and W. W. Scott, Jr.: Electric Furnace Proceedings, AIME, New York, (1974), 29.

2) J. W. Brown and R. L. Reddy: Iron Steel Eng., 53 (1976), 37.

3) T. Kishida, T. Kitizawa, S. Fujita, Y. Fukumoto and K. Mogi: Proceedings of the 1st Venezuela-Japan Symposium on Iron and Steelmaking, Caracas, May 1980, I.V.I.C. and CONICIT, Caracas, (1981), 263.

4) C. D. Davis: Electric Furnace Proceedings, AIME, New York, (1974), 37.

5) G. Post and D. Ameling: Electric Furnace Proceedings, AIME, New York, (1974), 21.

6) J. F. Elliott, J. Nauman and K. Sadrnezhaad: Proceedings of the International Iron and Steel Congress, TMS-AIME, Chicago, (1978), 397.

7) A. Sato, R. Nakagawa, S. Yoshimatsu, A. Fukuzawa, T. Ozaki, K. Kasahara, Y. Fukuzawa and T. Mitsui: Trans. ISIJ, 19 (1979), 112.

8) A. Sato, K. Kasahara, R. Nakagawa, S. Yoshimatsu, A. Fukusawa, T. Ozaki, Y. Iwai, Y. Fukuzawa and T. Mitsui: Trans. ISIJ, 19 (1979), 490.

9) Y. Ukim and R. Pehlke: Met. Trans., 5 (1974), 2527.

10) R. G. Olsson, V. Koump and T. F. Perzak: Trans. Met. Soc. AIME, 233 (1965), 1654.

11) J. Szekely, Y. K. Chuang and J. W. Hinkla: Met. Trans., 3 (1972), 2825.

12) Y. K. Ghuang and J. Szekely: Int'l J. of Heat and Mass Transfer, 17 (1974), 945.

13) O. Ehrich, Y. K. Chuang and K. Schwerdtfeger: Int'l J. of Heat and Mass Transfer, 21 (1978), 341.

14) O. Ehrich, Y. K. Chuang and K. Schwerdtfeger: Arch. Eisenhüttenw., 50 (1979), 329.

15) O. Ehrich: "Theoretische Untersuchung Zum Einschmelzen von Eisenschwammpellets in Induktionstiegelofen ", Thesis Dissertation, Universität Glausthal, F. R. Germany, (1978). 